\title{
Correction to: Nondestructive Quantitative Inspection of Drug Products Using Benchtop NMR Relaxometry-the Case of NovoMix® 30
}

\author{
Katharine T. Briggs, ${ }^{1}$ Marc B. Taraban, ${ }^{1}$ Weizhen Wang, ${ }^{2,3}$ and Y. Bruce Yu ${ }^{1,4}$
}

published online 6 June 2019

\section{Correction to: AAPS PharmSciTech (2019) 20:189 \\ https:/doi.org/10.1208/s12249-019-1405-0}

Typesetting error occurred and author corrections to the equations and text edits at the proofing stage were not incorporated in the published article. The original article has been corrected.

Publisher's Note Springer Nature remains neutral with regard to jurisdictional claims in published maps and institutional affiliations.

The online version of the original article can be found at https:// doi.org/10.1208/s12249-019-1405-0

${ }^{1}$ Department of Pharmaceutical Sciences and Bio- and NanoTechnology Center, University of Maryland, 20 Penn Street, Baltimore, Maryland 21201, USA.

${ }^{2}$ Department of Statistics, Tianjin University of Finance and Economics, Tianjin, 300222, People's Republic of China.

${ }^{3}$ Department of Mathematics and Statistics, Wright State University, Dayton, Ohio 45435, USA.

${ }^{4}$ To whom correspondence should be addressed. (e-mail: byu@rx.umaryland.edu) 